THE $11^{\text {TH }}$ EDITION OF

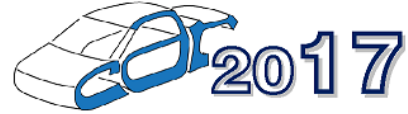

The International Congress of Automotive and Transport Engineering

MOBILITY ENGINEERING AND ENVIRONMENT

November 8-10, 2017

\title{
Considerations concerning the power loops within the all- wheel driven transmissions of the automobile
}

\author{
M Truţă ", B Laszlo, D Voicu, R Stoica and V Vînturiş \\ Military Technical Academy, Dept. of Military Automotive and Transportation \\ *Corresponding author e-mail: truta_marian@yahoo.com
}

Article history

Received 20.06.2017

Accepted 22.09.2017

DOI https://doi.org/10.26825/bup.ar.2017.013

\begin{abstract}
This paper aims at analyzing the ways the power loop magnitude varies within the $4 \times 4$, inter-axle transmission of and automobile, according to different parameters. More accurate, it aims at determining the way the power loop magnitude varies according to the variation of the tire radii difference between the front and the rear axle.

To achieving the paper's goals, a set of specialized tests has been developed, using a military APC with a $4 \times 4$ driveline. The dedicated vehicle was the reconnaissance vehicle TAB C-79. To reveal the power loop between the axles, we needed to measure the torque and the angular speed within different relevant spots of the driveline. Specialized sensors have been used together with a GPS VBOX Mini equipment.

The experimental results have been illustrated within a series of charts providing the power loop's magnitude time history in different situations. A complex analysis of these data led to useful scientific conclusions.

As a novelty, this paper presents a set of conclusions concerning the power loops when the vehicle was rolling on a concrete surface. We cold say that this paper clarifies the way to determine the power loop occurrence and also its magnitude within the trans-axle transmission when taking into account various factors. Moreover, the conclusions can be used to identify the necessary measures to be taken to diminishing the power loop at the longitudinal level of the automobile's driveline.
\end{abstract}

\section{Introduction}

The all-wheel driven transmission yet has a big problem: the self generated torque that occurs inside the driveline. The only way to override the wind-up torque, occurred inside of a normal driveline, is to increase the power delivered by the engine. On the other hand, this power loss can't be used as a traction power for the automotive. Hence, it leads to extra fuel consumption, 
supplementary wear of the driveline's components and of the tires. Nevertheless, decreased maneuverability should be taken into account $[2,8,9]$.

This paper performs an analysis of the ways the power loops vary along the inter-axle driveline of a $4 \times 4$ automobile with respect to some certain parameters.

The loop power-flow is the power that loads a closed loop of the transmission driveline and it is not generated by the automobile's driving or by coasting processes. Mathematically speaking, it is computed by gaining the self-generated torque on some component with that component's angular speed [6].

The cause generating the power loops between the vehicle's axles is the difference between the wheels' travel. At its turn, a major reason to have different wheels travel is the unevenness of the rolling radii. Within this paper, whenever the tire radii difference is called, we assumed the tire radii difference between axles, since the tires of the same axis have the same rolling radii.

Many papers have developed studies with respect to the analyzed problem $[2,4,5]$.

\section{Theoretical notions with respect to the power loops between axles}

We hereby present some theoretical notions concerning the power loop between a all-driven transmission of a vehicle.

The balance of power in the situation described, according to the literature, is given by [6]:

$$
P_{m o t} \eta_{T_{M-S}}=\varphi Z_{S} r_{r_{S}} \omega_{r}-\left(\varphi Z_{S}-\sum R\right) r_{r_{F}} \omega_{r} \eta_{T_{F-C D}}
$$

Equation 1 gives the power balance within the transmission, at the longitudinal level, and also makes a good analysis of the components of the power flow inside the driveline for the specific driving conditions. If considering the terms of this equation, following identifications are possible: $P_{m o t} \eta_{T_{M-S}}$ is the engine's output as input for the transfer case; $\varphi Z_{S} r_{r_{S}} \omega_{r}$ is the grip power and $\left(\varphi Z_{S}-\sum R\right) r_{r_{F}} \omega_{r} \eta_{T_{F-C D}}$ is the self-generated power.

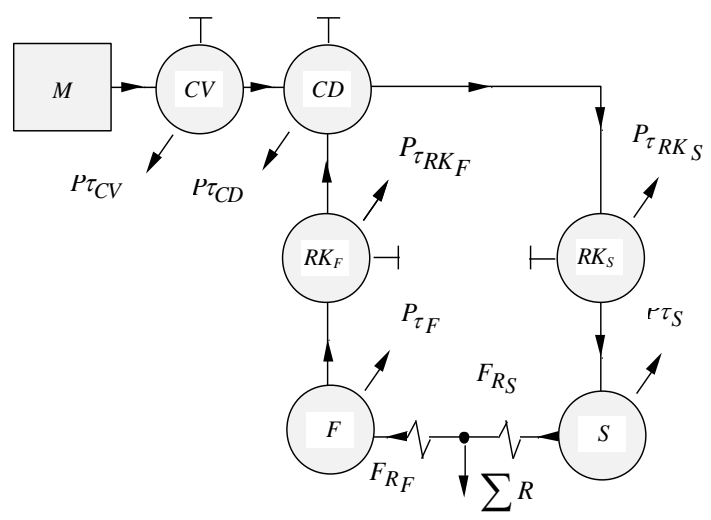

Figure 1. Front-to-back loop powerflow graph of a $4 \times 4$ vehicle.

In the previous formulae, $P_{m o t}$ is the power that comes from the vehicle's engine, $\eta_{T_{M-S}}$ is the engine-to-rear axle circuit's efficiency, $\eta_{T_{F-C D}}$ is the front axle-to-central differential circuit's efficiency, $\varphi$ is the adherence limit, $Z_{S}$ is the rear axle's vertical load and $\omega_{r}$ is the wheel's angular speed. Should also be mentioned that $r_{r_{F}}$ and $r_{r_{S}}$ are the front and rear tire radii respectively. The rear wheels radius can differ from the front ones but the wheels of the same axle are equal to each other. We also assumed that the angular speed is the same to the rear and front axle's wheels [2]. $\sum R$ is total drag while. 
On the other hand, the power flow driven to the front axle is given by equation 4 , where, along the already defined terms, we yet have $r_{c}$ as the cinematic tire radius and $k_{e}$ as the tire's elasticity [2].

$$
P_{F}=\frac{r_{r} \eta_{T_{F-S}}}{1+\cos \alpha}\left[\sum R-\frac{r_{c}}{k_{e}}(1-\cos \alpha)\right] \omega_{r}
$$

These flows can be noticed in figure 1 [7]. In these figures $M$ stands for engine, $A$ is the clutch, $\mathrm{CV}$ stands for gearbox, CD stands for the transfer case with an open, lockable differential, RK stands for final drive's transmission ratio, $\mathrm{F}$ and $\mathrm{S}$ stand for front and rear wheels respectively while $\mathrm{P} \tau$ represents the power losses (heat). Also, $\sum \boldsymbol{R}$ is total drag, $\mathrm{v}$ is the vehicle's speed, $\boldsymbol{P}_{\boldsymbol{m o t}}$ is the engine's output power, $\boldsymbol{F}_{\boldsymbol{R} \boldsymbol{F}}, \boldsymbol{F}_{\boldsymbol{R} S}$ are the driving forces at front and rear axle, respectively and $\boldsymbol{P}_{\boldsymbol{F}-\boldsymbol{S}}$ is the loop power-flow between axles [7].

\section{Experimental research}

To achieve the goals, some transducers were mounted on different components of the driveline (figure 2 [4]). So, on the shaft between the engine and the central differential were mounted a Wheatstone bridge to get the engine's torque and an inductive angular speed transducer. On the shafts between the rear and the front axle, on one hand and the central differential on the other hand, were also mounted Wheatstone bridges to get the torque and optical angular speed transducers $[1,2]$.

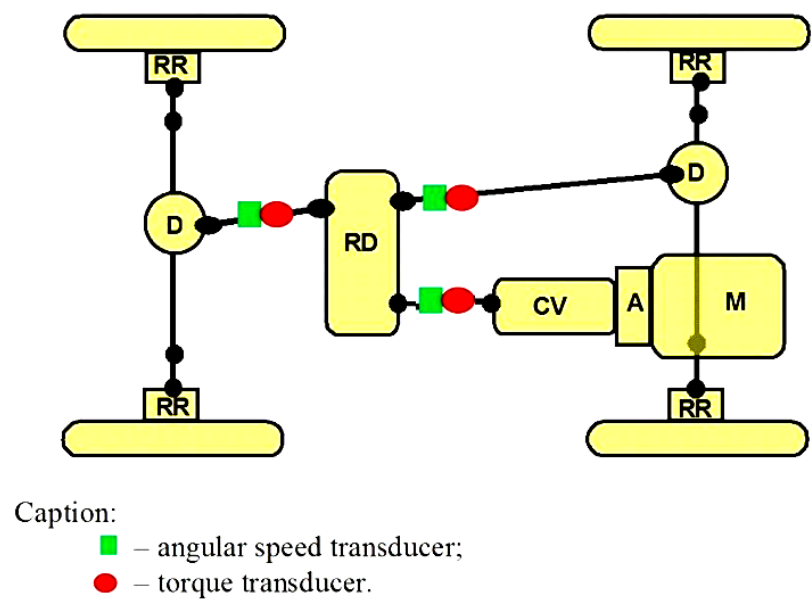

$a$

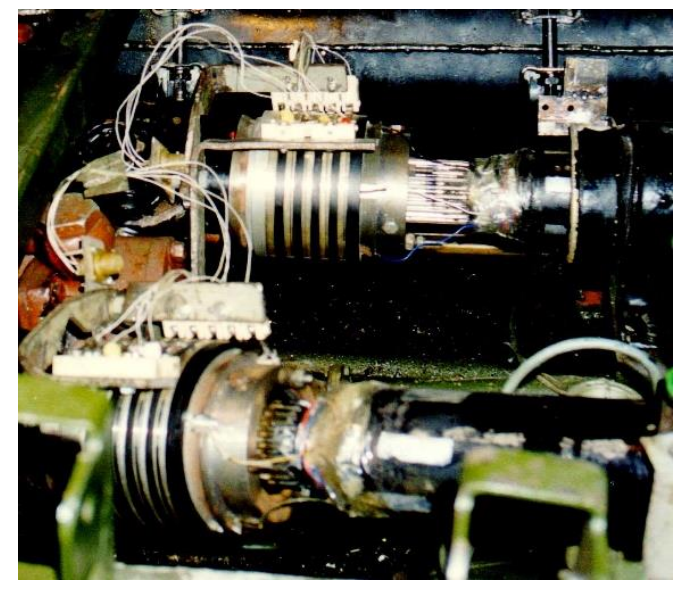

$b$

Figure 2. Mounting the transducers to reveal the loop power-flow.

Figure 2-a uses the following abbreviations: $\mathrm{M}$ - engine; A - clutch; $\mathrm{CV}$ - gearbox; RD transfer case with open, lockable differential; D - transversal differential; RR - hub gear. Figure 2$b[3]$ it is represents the torque acting on a transmission shaft of a military vehicle.

The tests have been developed under three circumstances, as follows:

- no tire rolling difference between axles

- $30 \mathrm{~mm}$ tire rolling difference between axles (rear axle having larger rolling radius)

- $60 \mathrm{~mm}$ tire rolling difference between axles (rear axle having larger rolling radius)

To experimentally assess the rolling radii we used:

$$
P_{F}=\frac{S}{2 \pi}
$$

where $\mathrm{S}$ is the travel of a wheel when taking a complete rotation.

Technically, to experimentally determine the rolling radius of a tire $\left(r_{r}\right)$ we made a mark on the tire (with the wheel in working position) and traveled 5 complete turns of the wheel. We measured the traveled distance then we used equation (3) to compute the rolling radius.

We used: 


$$
\Delta r=\left|r_{r_{S}}-r_{r_{F}}\right|
$$

to determine the tire rolling difference between the front and rear axle's wheels.

The measurements performed to determining the variation of the self-generated power between the axles took into account the rolling resistance of the APC. To having a controlled rolling resistance we have created a convoy made of the tested vehicle towing a heavy military truck. The rolling resistance variation has been simulated by progressively braking the towed truck

\section{Results}

We studied all the charted plots when the vehicle was traveling on concrete to achieving a complete analysis of the self-generated power magnitude's variation when the rolling resistance varies. In this respect, we had a great interest in the following charts that provide information about the variation of the self-generated power:

- engine to transfer case;

- transfer case to front axle (self-generated power);

- transfer case to rear axle.

The objectives of the paper are achieved by identifying the shape and the slope of the curves that describe the evolution of the analyzed power flows.

When analyzing the figure 3 (up) one could notice that all the power fluxes are positive when traveling on concrete, normal drive and no tire radii difference. It can also be noticed that the power evolution on the input shaft of the transfer case consists of an increasing stage, followed by a constant development of the magnitude to about $14 \mathrm{~kW}$. A steep evolution can be noticed as the towed vehicle is progressively braked (simulating an increase of the rolling resistance).
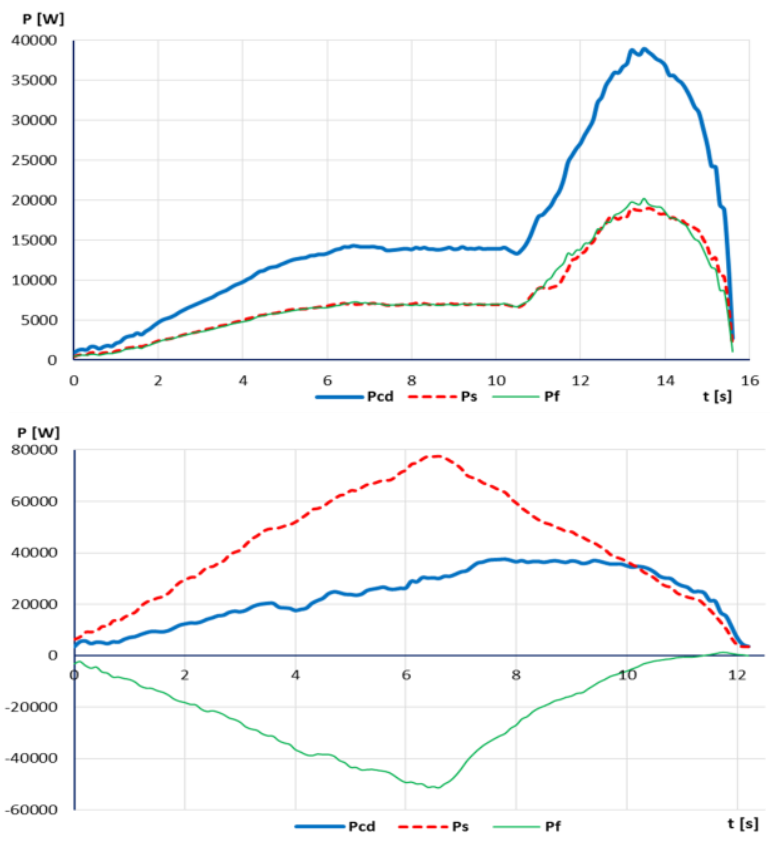

Figure 3. Power fluxes variation within the vehicle's driveline for $\Delta r=0 \mathrm{~mm}$ (up) and $\Delta r=30 \mathrm{~mm}$ (down) when rolling on concrete.

On the other hand, the power flux evolution on the input shaft of the transfer case grows up to its maximum value of $39 \mathrm{~kW}$ and it is followed by a sudden decrease down to a complete disappearance, as the towed vehicle is braked. The powers on the front and rear output shafts of the transfer case are similar to the one on the input shaft of the transfer case, yet their values are 
constant and closed to $7.5 \mathrm{~kW}$ during the taking off stage. Their maximum value is about $20 \mathrm{~kW}$. They are reached during braking the towed vehicle and they rapidly decrease to null.

Analyzing the chart of the power variation within the same conditions but considering a tire radii difference of $0.03 \mathrm{~m}$ (figure 3 - down), one could notice that the power on the rear axle (Ps) is permanently positive, as the input shaft's one is (Pcd). Nevertheless, the power on the front output shaft (towards the front axle) is mostly negative. To underlining the evolution of the studied phenomenon we should recall that the positive power makes the vehicle moving while the negative ones (closed loop power) don't.

Studying the shapes of the power curves delivered to the rear axle and the front one respectively, we could notice that they are similar but the main discrepancy is that one of them is positive while the other one is negative.

From the magnitude point of view, the output power towards the front axle (Pf) continuously decrease during the take off stage down to a minimum of about $-50 \mathrm{~kW}$. It is followed by an increase of its value during the towed vehicle braking stage until reaching positive values. It means that the front axle becomes, briefly, a driving axle.

As the theory predicts, a difference between the tire radii (between the axles) induces selfgenerated power. When the rolling resistance is high, the power towards the front axles briefly becomes positive, at the very end of the test.

Studying the researched parameters when the tire radii difference is of $0.06 \mathrm{~m}$ (figure $4-\mathrm{up}$ ), we could notice a similar behavior to the previous case (when the difference was of $0.03 \mathrm{~m}$ ). The only difference consists of the larger magnitude of the power towards the front axle, also negative: $P_{f \text { min }} \approx 52 \mathrm{~kW}$.
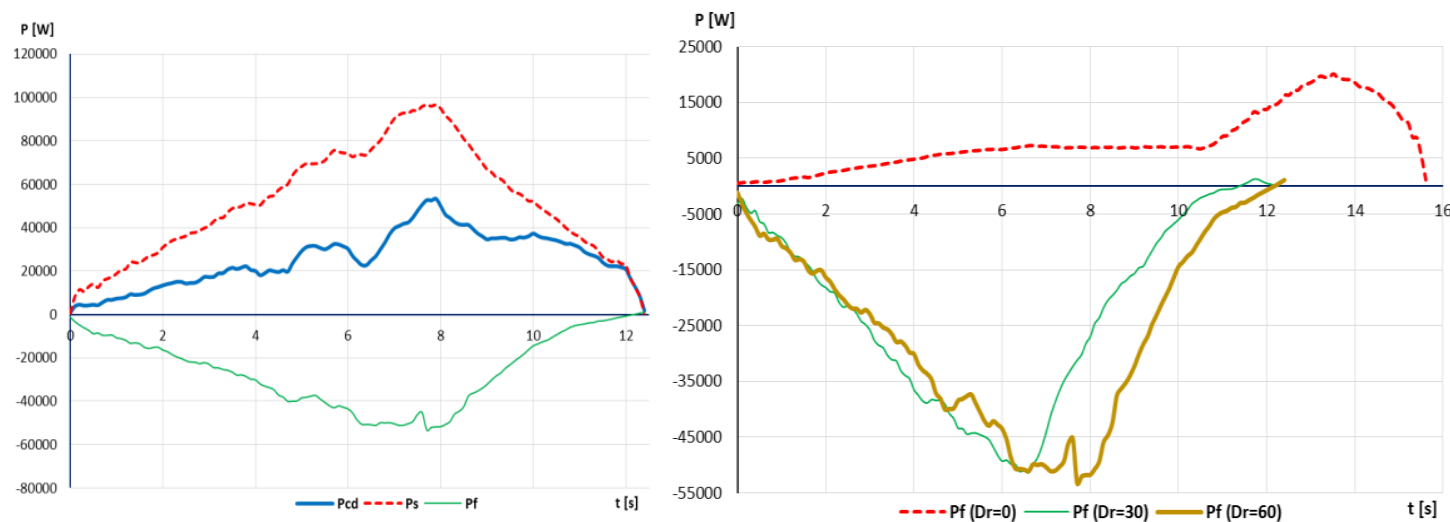

Figure 4. Power fluxes variation within the vehicle's driveline for $\Delta r=60 \mathrm{~mm}$ (up) and for all the cases $\Delta r=0 \mathrm{~mm}, \Delta r=30 \mathrm{~mm}, \Delta r=60 \mathrm{~mm}$ (down) when rolling on concrete.

\section{Conclusions}

The mathematical model given in this paper was confirmed by the large amount of data achieved during the developed tests. The main problems within the 4WD drivetrains are the self-generated torque and consequently the looping power that occurs

Examining the charts 3 şi 4 we could notice:

- the self-generated power didn't occur when the tire radii were the same;

- $\quad$ the self-generated power occurred when there was a difference between the tire radii;

- $\quad$ the self-generated power increases with the tire radii difference;

- when the tire rolling difference increases, the slope of the power on the output shaft towards the front axle increases.

Whenever a difference between the tire rolling radii occurs, a cinematic misfit occurs and it becomes responsible of the power loops occurrence at the longitudinal level of an all terrain vehicle driveline. 


\section{References}

[1] Puncioiu A M, Truţă M, Marinescu M, Grosu D and Vînturiş V 2015 International Journal of Modern Manufacturing Technologies Vol VII, No. 2 ISSN 2067-3604 pp 85-89

[2] Truţă M, Marinescu M, Vilău R, Alexa O and Ilie C O 2014 Applied Mechanics and Materials, Advanced Concepts in Mechanical Engineering II Vol 659 doi: 10.4028/www.scientific.net/AMM.659.268 pp 268-273

[3] Vilău R, Marinescu M, Alexa O, Oloeriu F and Truţă M Advanced Materials Research, Modern Technologies in Industrial Engineering II Vol 1036 doi: 10.4028/www.scientific.net/AMR.1036.493 pp 493-498

[4] Truţă M, Puncioiu A M, Marinescu M and Vînturiş V 2015 MTA Review Vol XXV No 3 pp 391-396

[5] Truţă M, Marinescu M and Vînturiş V 2016 IOP Conf. Series: Materials Science and Engineering doi:10.1088/1757-899X/147/1/012131

[6] Truţă M, Costache D, Marinescu M, Vînturiş V and Mitrea M 2012 MTA Review Vol XXII No 1 pp 19-30

[7] Truţă M, Puncioiu A M and Vînturiş V 2012 MTA Review Vol XXII No 1 pp 19-30

[8] Alexa O, Vilău R, Ilie C O, Voicu D, Marinescu M 2016 International Congress of Automotive and Transport Engineering ISBN 978-3-319-45447-4-39 pp 348-353

[9] Alexa O, Ilie C O, Marinescu M, Vilău R, Grosu D 2015 Modern Technologies in Industrial Engineering 